Eduardo Remor'

Jenny Milner-Moskovics"

Gisele Preussler"
Facultad de Psicología. Universidad Autónoma de Madrid. Madrid, España

Centro Municipal de Atendimento às DST/Aids. Secretaria Municipal da Saúde de Porto Alegre. Porto Alegre, RS, Brasil

Correspondência | Correspondence: Eduardo Remor

Departamento de Psicología Biológica y de la Salud

Facultad de Psicología C/ Ivan Pavlov, 6

Universidad Autónoma de Madrid

28049 Madrid, España

E-mail: eduardo.remor@uam.es

\section{Adaptação brasileira do "Cuestionario para la Evaluación de la Adhesión al Tratamiento Antiretroviral"}

\author{
Brazilian adaptation of the \\ Assessment of Adherence to \\ Antiretroviral Therapy Questionnaire
}

\section{RESUMO}

OBJETIVO: O “Cuestionario para la Evaluación de la Adhesión al Tratamiento Antiretroviral" é um instrumento auto-aplicável para a identificação do grau de adesão ao tratamento anti-retroviral em pacientes com infecção pelo HIV. O objetivo do estudo foi de traduzir, adaptar e validar o questionário para seu uso no Brasil.

MÉTODOS: O questionário foi traduzido do original em espanhol ao português, utilizando o processo de tradução-retradução (espanhol/português/ espanhol), seguido de avaliação verbal da compreensão com um pequeno grupo de pacientes. Foram estudadas as propriedades psicométricas do instrumento em uma amostra de 59 pacientes com infecção pelo HIV em tratamento antiretroviral. Os pacientes foram avaliados em centro especializado no atendimento de pacientes infectados pelo HIV ou com Aids, em Porto Alegre, Rio Grande do Sul, entre os meses de junho a novembro de 2005. Para o processo de validação do instrumento foram analisados os indicadores de consistência interna, validez relacionada a um critério externo, sensibilidade e especificidade.

RESULTADOS: A análise dos resultados permitiu identificar uma adequada confiabilidade do questionário $(\alpha=0,64)$ e validade relacionada a um critério externo (carga viral; $\mathrm{r}=-0,48 ; \mathrm{p}<0,001$ ). Também observou-se adequada sensibilidade $(79,2 \%)$ e especificidade $(57,1 \%)$ do questionário para a detecção entre indivíduos com carga viral indetectável e detectável.

CONCLUSÕES: A versão em português do Questionário para Avaliação da Adesão ao Tratamento Anti-retroviral mostrou ser útil, confiável e válida para a avaliação do grau de adesão ao tratamento anti-retroviral em pacientes com infecção pelo HIV.

DESCRITORES: Síndrome de imunodeficiência adquirida, prevenção e controle. Agentes anti-HIV, provisão e distribuição. Resultado de tratamento. Questionários. Tradução (Produto). Estudos de validação [Tipo de publicação]. 


\begin{abstract}
OBJECTIVE: The "Cuestionario para la Evaluación de la Adhesión al Tratamiento Antiretroviral" (Assessment of Adherence to Antiretroviral Therapy Questionnaire) is a self-administered instrument for the assessment of adherence rates to antiretroviral therapy in HIV-infected patients. The objective of the present study was to translate, adapt and validate the questionnaire for its use in Brazil.
\end{abstract}

METHODS: The questionnaire was translated from the Spanish original into Brazilian Portuguese using the forward-backward translation method (Spanish/Portuguese/Spanish), followed by verbal assessment of understanding in a small group of patients. Then the instrument's psychometric properties were studied in a sample of 59 HIV-infected patients under antiretroviral therapy. Patients were interviewed in an HIV/ AIDS clinic in the city of Porto Alegre, Southern Brazil, between June and November 2005. The validation process of the questionnaire's reliability included the analysis of internal consistency, external criterion-related validity, sensitivity, and specificity.

RESULTS: The results showed the questionnaire's adequate reliability $(\alpha=0.64)$ and external criterion-related validity (viral load; $r=-0.48 ; p<0.001$ ). Adequate sensitivity (79.2\%) and specificity (57.1\%) for the detection of subjects with detectable versus undetectable viral loads were also found.

CONCLUSIONS: The Brazilian Portuguese version of the questionnaire proved to be useful, reliable and valid for the assessment of adherence rates to antiretroviral therapy in patients living with HIV.

KEY WORDS: Acquired immunodeficiency syndrome, prevention \& control. Anti-HIV agents, supply \& distribution. Treatment outcome. Questionnaires. Translations. Validation studies [Publication type].

\section{INTRODUÇÃO}

Atualmente existem no Brasil cerca de 371.800 casos de Aids notificados. A taxa de incidência de Aids tem se mantido em patamares elevados: 7,2 casos por 100.000 habitantes. Tem se verificado aumento gradativo de mulheres entre os casos notificados. A mortalidade por Aids mantém-se estabilizada em cerca de $11 \mathrm{mil}$ óbitos anuais desde 2002 e o número total de óbitos por Aids no Brasil já atingiu 171.923 casos.* Apesar dos alarmantes dados epidemiológicos e dos esforços de prevenção da infecção pelo HIV no Brasil, a epidemia do vírus continua em expansão.

Por outro lado, a partir da implementação da política de acesso universal e gratuito à terapia anti-retroviral (TARV) em 1996, observou-se um novo perfil para o tratamento da Aids. A qualidade de vida dos portadores de HIV melhorou e as internações hospitalares e a mortalidade por Aids diminuíram em cerca de 30\%.* $\mathrm{O}$ número de pacientes que utilizam anti-retrovirais no
Brasil tem aumentado de 36.000 em 1997 a 170.000 em 2005. Há estimativas de que em 2008 este número alcançará 215 mil pessoas. **

No entanto, como conseqüência dessa política de saúde, a adesão ao tratamento tornou-se o novo desafio para os gestores das políticas de DST/Aids, assim como para os serviços de saúde diretamente envolvidos no atendimento aos portadores de HIV no Brasil. Quando a medicação é tomada de maneira inadequada ou insuficiente (lapsos, falhas nos dias ou horários), contribui para a criação de cepas virais multirresistentes e a conseqüente falência terapêutica. Isso gera desperdício do investimento na pesquisa e desenvolvimento de drogas, acarretando prejuízos tanto no âmbito individual quanto no coletivo. ${ }^{11}$ A maior parte dos estudos preconizam taxas de ingestão iguais ou acima de $80 \%$ do total de medicamentos prescritos para a obtenção de efetividade terapêutica. ${ }^{6,11,18}$

\footnotetext{
* Ministério da Saúde. Coordenação Nacional de DST e Aids. Dados Epidemiológicos Aids. Bol Epidemiol AIDS DST. 2005;2(1).

** Ministério da Saúde. Programa nacional de DST-AIDS. Tratamento de HIV e Aids: Medicamentos. Disponível em: http://www.aids.gov.

br/data/Pages/LUMIS9DDD0E43PTBRIE.htm [Acesso em 14 Jun 2007].
} 
Portanto, além de investir em medicamentos e exames, é necessário também fazê-lo no treinamento das equipes de saúde, para que sejam capazes de compreender e manejar os diversos fenômenos subjetivos e comportamentais dos pacientes e do seu contexto sociocultural. Segundo a Organização Mundial de Saúde (OMS),${ }^{18}$ os fatores socioeconômicos, assim como os relacionados ao serviço de saúde, à doença, ao tipo de tratamento e à pessoa em tratamento afetam diretamente a adesão à TARV, sendo essencial individualizar as estratégias.

É de fundamental importância incrementar as estratégias de intervenção dos serviços de saúde e avaliá-las a partir da compreensão dos fatores associados à adesão. Segundo o Ministério da Saúde, * características como baixa escolaridade e ausência de renda pessoal estão associadas com a não-adesão, independentemente do esquema de medicação utilizado, da unidade de saúde e da quantidade de faltas ao seguimento médico. Isso aponta a necessidade de atenção mais específica para os pacientes de baixo nível socioeconômico.

Nos últimos anos, diversos estudos ${ }^{1,8,11,18}$ enfatizaram a importância da adesão ao tratamento para que os fármacos anti-retrovirais atuassem de forma eficaz. A partir desta constatação, a avaliação e seguimento da adesão ao tratamento passou a ser prioridade no âmbito da saúde pública e Aids. Uma série de mecanismos foram postos em prática para o controle deste aspecto, por exemplo, a utilização de indicadores de medida diretos e indiretos para a identificação de pacientes com uma adesão ao tratamento insuficiente. Com o avanço das pesquisas, constatou-se que tanto métodos diretos (mais caros, invasivos e complexos) como indiretos (auto-informe) eram igualmente úteis e válidos para esse objetivo, abrindo a porta para a utilização de questionários (psicometricamente avaliados) para avaliar a adesão ao tratamento farmacológico.

Embora a política de acesso universal e gratuito aos anti-retrovirais do Brasil seja reconhecida internacionalmente, ainda há carência de estudos publicados** que avaliem a eficácia das estratégias implementadas para garantir uma adequada adesão ao tratamento ou melhorá-la. ${ }^{4}$ No mesmo sentido, há poucas ferramentas padronizadas e desenvolvidas especificamente para avaliar os resultados dos programas de adesão ao tratamento do HIV/Aids, ou mesmo como medida de controle da ingestão de medicamento em ensaios clínicos com novos medicamentos.
Com o objetivo de preencher essas lacunas, o presente estudo teve por objetivo traduzir, adaptar e validar o "Cuestionario para la Evaluación de la Adhesión al Tratamiento Antirretroviral” (CEAT-VIH) para a população brasileira.

\section{MÉTODOS}

CEAT-VIH ${ }^{11,13, * * *}$ é um instrumento de auto-informe com 20 perguntas que em seu conjunto avaliam o grau de adesão ao tratamento anti-retroviral. Aplicável a pacientes adultos com infecção pelo HIV, é uma ferramenta rápida e simples de administrar, e fácil para o paciente responder. Além disso, tem caráter multidimensional, pois abarca os principais fatores que podem modular o comportamento de adesão ao tratamento. Estudos prévios ${ }^{11,13, * * * *}$ mostraram a utilidade deste instrumento em outros países (Colômbia, Espanha, Peru e Portugal).

A versão em português do CEAT-VIH realizou-se mediante o procedimento de tradução e retraducão (forward-backward translation) por especialistas bilíngües português-espanhol de forma independente. A versão final foi aplicada a um número reduzido de pacientes, com o objetivo de testar a compreensão dos itens do questionário. Pequenos ajustes na linguagem foram necessários como conseqüência das sugestões dos pacientes. A versão final do questionário apresentase em anexo. A pontuação total é obtida pela soma de todos os itens (valor mínimo possível 17, valor máximo possível 89). Quanto maior a pontuação, maior o grau de adesão ao tratamento.

Para validação do CEAT-VIH foi selecionada uma amostra de 59 pacientes em tratamento anti-retroviral, de um centro especializado no atendimento de pacientes infectados pelo HIV ou com Aids, em Porto Alegre, Rio Grande do Sul. A coleta de dados foi realizada entre os meses de junho a novembro de 2005. Foram convidadas de forma consecutiva todas as pessoas que preenchiam os critérios de inclusão (HIV+, estar em tratamento anti-retroviral há mais de três meses). Foram excluídos os indivíduos que não eram alfabetizados, ou eram usuários de drogas ilícitas nos últimos seis meses da data de realização da pesquisa. A coleta de dados sociodemográficos realizou-se mediante entrevista estruturada construída para o estudo, incluindo-se: idade, sexo, situação laboral, nível de escolaridade, orienta-

\footnotetext{
* Ministério da Saúde. Programa Nacional de DST e Aids. Aderência ao tratamento por anti-retrovirais em serviços públicos no Estado de São Paulo. Brasília (DF): Ministério da Saúde; 2000.

** Nemes MIB, Marinho, MFS, Kalichman A, Grangeiro A, Alencar RS, Lopez JF. Prevalência da aderência e fatores associados. In: Nemes MIB, (Org.) Avaliação da aderência ao tratamento por antiretrovirais em usuários de ambulatórios do sistema público de assistência à Aids no Estado de São Paulo. Brasília (DF): Coordenação Nacional DST/Aids; 2000. p. 44-76. Série Avaliação nº 1.

*** Remor E. Manual del cuestionario para la evaluación de la adhesión al tratamiento antirretroviral (CEAT-VIH). Madrid: Facultad de Psicología-Universidad Autónoma de Madrid; 2002. Edição eletrônica em PDF revisada em 2007. Uma cópia do manual pode ser obtida mediante solicitação ao autor.

**** Reis A, Lencastre L, Guerra M. Portuguese Adaptation of the "Questionnaire to Assess Adherence to Antirretroviral Treatment - HIV". Libro de Resumenes del Symposium HISPANO-LUSO de Medicina Conductual y Psicología de la Salud. SEMC\&PS: Madrid, España 2007 Julio 5 - 7. Pág. 27
} 
ção sexual, classe socioeconômica, uso de medicação psiquiátrica e modo de transmissão do HIV. Os dados relativos ao perfil clínico dos pacientes foram compilados diretamente do prontuário: tempo de infecção por HIV (em meses), níveis de linfócitos T-CD4+ e carga viral plasmática, medicação anti-retroviral, número de comprimidos e posologia (freqüência).

Para avaliar a adesão ao tratamento foi utilizado o "Cuestionario para la Evaluación de la Adhesión al Tratamiento Antiretroviral (CEAT-VIH) de Remor, ${ }^{11,13}$ em sua versão brasileira adaptada.

Outro objetivo do estudo foi identificar a relação entre as crenças e expectativas em relação ao tratamento anti-retroviral e o grau de adesão ao tratamento informado. Com esse objetivo, utilizou-se o "Questionário de percepções e expectativas relacionadas com o tratamento anti-retroviral" de Remor, ${ }^{12}$ com perguntas referentes às expectativas positivas e otimismo frente aos resultados do tratamento (3 itens), percepção de dificuldades e problemas com o tratamento (2 itens), e percepção de mudanças positivas ou negativas decorrentes do tratamento ( 2 itens). As opções de resposta são apresentadas em escala Likert de cinco pontos e maior pontuação indica maior presença da variável. A confiabilidade (alfa de Cronbach) do questionário completo para a presente amostra foi de 0,50 .

Os pacientes preenchiam os instrumentos na presença do pesquisador, após assinatura do termo de consentimento esclarecido.

Posteriormente à comprovação do cumprimento dos supostos paramétricos das variáveis (normalidade e homocedasticidade), realizaram-se as análises descritivas da amostra: freqüências, médias e desvio-padrão (DP) das variáveis sociodemográficas, clínicas e laboratoriais consideradas. Também foi realizada uma descrição da freqüência de respostas nas variáveis relacionadas ao grau de adesão ao tratamento. Para analisar a relação entre as variáveis percepções e expectativas relacionadas com o tratamento anti-retroviral com a adesão ao tratamento, utilizou-se a correlação de Pearson. Para avaliar diferenças entre grupos, foi utilizada uma análise de variância (Anova). Para a análise da confiabilidade do questionário, calculou-se a consistência interna (alfa de Cronbach). Para identificar a sensibilidade e especificidade do questionário, procedeu-se à análise das curvas ROC (Receiver Operating Characteristic). ${ }^{10,19}$ Os dados foram tabulados e as análises estatísticas foram realizadas no programa SPSS/PC v14.0. Para a análise das curvas ROC, utilizou-se o programa MedCalc.

A pesquisa foi aprovada pelo Comitê de Ética e Pesquisa da Secretaria Municipal de Saúde de Porto Alegre. A participação foi voluntária e todos os participantes assinaram o Termo de Consentimento Livre e Esclarecido, pelo qual aceitavam as condições do estudo.

\section{RESULTADOS}

Os participantes tinham entre 24 e 72 anos de idade, média de 43,1 anos, 59\% do sexo masculino, 71,2\% possuíam ensino fundamental. Eram predominantemente de nível socioeconômico baixo $(45,8 \%)$ e médio baixo $(49,2 \%)$. A orientação sexual informada era predominantemente heterossexual (75\%). Do total da amostra, 88,1\% informou não utilizar medicação psiquiátrica. Quanto ao seu modo de infecção, predominou a via sexual (56\%), seguida da transmissão por uso de drogas injetáveis (29\%).O tempo de infecção médio foi de 80,9 meses, variando entre 3 e 178 meses. A média de linfócitos T-CD4+ foi de 371,20 e a carga viral plasmática média foi de $15.406,88$ cópias $/ \mathrm{mL} ; 59,3 \%$ apresentaram carga viral indetectável ( $<50$ cópias $/ \mathrm{mL})$. A descrição detalhada das variáveis sociodemográficas e clínicas estão na Tabela 1 .

Em média, os participantes ingeriam 7,5 comprimidos diariamente, variando entre zero e 33 comprimidos diários. As combinações de posologia predominantes foram: ingestão de comprimidos de 12/12 horas e de $24 / 24$ horas $(66,1 \%)$; ingestão de $12 / 12$ horas $(15,3 \%)$; e de $8 / 8,12 / 12$ e $24 / 24$ h $(5,1 \%)$. As combinações de fármacos mais comuns foram: 2 Inibidores da Transcriptase Reversa Análogo de Nucleosídeos (ITRN) + 1 Inibidor Transcriptase Reversa Não Análogo de Nucleosídeos (ITRNN) (30,5\%); 2 ITRN + 2 Inibidor da protease (IP) $(23,7 \%) ; 2$ ITRN + 1 IP $(18,6 \%)$ e 2 ITRN + 1 IP + 1 ITRNN (13,6\%). A combinação que requer maior número de comprimidos é a 2 ITRN + 1 IP (11,8 pílulas).

Não foi observada relação significativa entre a idade $(r=0,21 ; p=0,10)$, tempo de infecção por HIV em meses $(\mathrm{r}=-0,11 ; \mathrm{p}=0,39)$ e grau de adesão ao tratamento medido pelo CEAT-VIH. Do mesmo modo, não houve diferenças nas pontuações do CEAT-VIH por sexo $(\mathrm{t}[57]=1,134 ; \mathrm{p}=0,25)$ e em função da situação de trabalho $(\mathrm{t}[57]=0,301 ; \mathrm{p}=0,76)$. Portanto, o grau de adesão informado parece não estar em função das características sociodemográficas da amostra.

Para identificar a relação entre as características do tratamento e o grau de adesão ao tratamento medido pelo CEAT-VIH, realizou-se correlação entre o número de comprimidos ingeridos e a pontuação do questionário. Observou-se uma relação inversa entre as variáveis, porém estatisticamente não significativa $(r=-0,06$; $\mathrm{p}=0,63)$. A relação entre o número de comprimidos e a carga viral $(r=0,32 ; p=0,01)$ foi significativa e positiva, o que sugere que o número de comprimidos parece ser uma barreira para uma adesão ao tratamento. A análise gráfica desta relação (gráfico não apresentado) permitiu identificar que o decréscimo na adesão informada se reduz a partir de dez comprimidos, e também o aumento da carga viral. 
Tabela 1. Distribuição da amostra de pacientes, segundo dados sociodemográficos e clínicos. Porto Alegre, RS, 2005. $\mathrm{N}=59$

\begin{tabular}{|c|c|c|c|}
\hline $\begin{array}{l}\text { Dado } \\
\text { sociodemográfico }\end{array}$ & $\%$ & $\begin{array}{c}\text { Média } \\
\text { (mínimo- } \\
\text { máximo) }\end{array}$ & DP \\
\hline Idade & & $\begin{array}{c}43,1 \\
(24-72)\end{array}$ & 11,2 \\
\hline \multicolumn{4}{|l|}{ Escolaridade } \\
\hline Sem estudos & 1,7 & & \\
\hline $\begin{array}{l}\text { Ensino } \\
\text { fundamental } \\
\left.\text { ( } 1^{\mathrm{a}} \text { a } 8^{\mathrm{a}} \text { série }\right)\end{array}$ & 71,2 & & \\
\hline Ensino médio & 27,1 & & \\
\hline Ensino superior & 0 & & \\
\hline \multicolumn{4}{|l|}{ Sexo } \\
\hline Feminino & 41 & & \\
\hline Masculino & 59 & & \\
\hline \multicolumn{4}{|l|}{ Situação de trabalho } \\
\hline Trabalha & 75 & & \\
\hline Não trabalha & 19 & & \\
\hline \multicolumn{4}{|l|}{ Orientação sexual } \\
\hline Heterossexual & 75 & & \\
\hline Homossexual & 19 & & \\
\hline Bissexual & 5 & & \\
\hline Não respondeu & 1 & & \\
\hline \multicolumn{4}{|l|}{ Forma de transmissão } \\
\hline Sexual & 56 & & \\
\hline $\begin{array}{l}\text { Usuários de } \\
\text { drogas injetáveis }\end{array}$ & 29 & & \\
\hline $\begin{array}{l}\text { Transfusão de } \\
\text { hemoderivados }\end{array}$ & 3 & & \\
\hline Não sabe & 12 & & \\
\hline \multicolumn{4}{|l|}{ Nível socioeconômico } \\
\hline Baixo & 45,8 & & \\
\hline Médio baixo & 49,2 & & \\
\hline Médio alto & 5,0 & & \\
\hline Alto & 0 & & \\
\hline \multicolumn{4}{|l|}{ Dados clínicos } \\
\hline $\begin{array}{l}\text { Tempo infecção HIV } \\
\text { (meses) }\end{array}$ & & $\begin{array}{c}80,9 \\
(3-178)\end{array}$ & 47 \\
\hline \multicolumn{4}{|l|}{$\begin{array}{l}\text { Uso de medicação } \\
\text { psiquiátrica }\end{array}$} \\
\hline Sim & 10,2 & & \\
\hline Não & 89,8 & & \\
\hline $\begin{array}{l}\text { Células CD4+ por } \\
\mathrm{mm}^{3} \text { de sangue }\end{array}$ & & $\begin{array}{c}371,20 \\
(27-1.110)\end{array}$ & 240,06 \\
\hline $\begin{array}{l}\text { Carga viral } \\
\text { (cópias/mL) }\end{array}$ & & $\begin{array}{c}15.406,88 \\
(0-484.072)\end{array}$ & $65.152,75$ \\
\hline $\begin{array}{l}<50 \text { (indetec- } \\
\text { tável) }\end{array}$ & 59,3 & & \\
\hline $51-400$ & 11,9 & & \\
\hline $401-30.000$ & 16,9 & & \\
\hline$>30.000$ & 11,9 & & \\
\hline
\end{tabular}

Tabela 2. Resultados das respostas aos itens do questionário CEAT-VIH. Porto Alegre, RS, 2005.

\begin{tabular}{|c|c|c|c|}
\hline $\begin{array}{l}\text { Item } \\
\text { (alternativas } \\
\text { de resposta) }\end{array}$ & Média & $\begin{array}{l}\text { Correlação } \\
\text { item-total } \\
\text { corrigida* }\end{array}$ & $\begin{array}{c}\text { Alfa de Cronbach } \\
\text { com a eliminação } \\
\text { do item** }\end{array}$ \\
\hline Item $1(1-5)$ & 4,61 & 0,53 & 0,57 \\
\hline Item $2(1-5)$ & 4,81 & 0,65 & 0,56 \\
\hline Item $3(1-5)$ & 4,76 & 0,60 & 0,56 \\
\hline Item $4(1-5)$ & 4,81 & 0,65 & 0,56 \\
\hline Items $5(0-2)$ & 1,03 & $-0,11$ & 0,64 \\
\hline Item 6 (1-5) & 4,85 & 0,10 & 0,62 \\
\hline Item 7 (1-5) & 3,98 & 0,34 & 0,59 \\
\hline Item $8(1-5)$ & 3,17 & 0,08 & 0,64 \\
\hline Item $9(1-5)$ & 4,64 & 0,18 & 0,62 \\
\hline Item $10(1-5)$ & 3,85 & 0,28 & 0,61 \\
\hline Item $11(1-5)$ & 4,81 & 0,35 & 0,61 \\
\hline Item $12(1-5)$ & 4,69 & 0,29 & 0,61 \\
\hline Item $13(1-5)$ & 4,58 & $-0,04$ & 0,65 \\
\hline Item $14(1-5)$ & 4,17 & 0,24 & 0,61 \\
\hline Item $15(1-5)$ & 3,80 & $-0,04$ & 0,66 \\
\hline Item $16(1-5)$ & 4,86 & 0,07 & 0,63 \\
\hline Item 17 (1-5) & 4,25 & 0,19 & 0,62 \\
\hline Item $18(1-5)$ & 4,69 & 0,28 & 0,61 \\
\hline Item $19(0-1)$ & 0,66 & $-0,13$ & 0,64 \\
\hline Item $20(0-1)$ & 0,22 & 0,09 & 0,63 \\
\hline
\end{tabular}

Não houve respostas em branco (esperada $0 \%$ )

* esperada $>0,10$

** esperável ao eliminar o item: o alfa total $(0,64)$ não aumenta.

CEAT-VIH: Cuestionario para la Evaluación de la Adhesión al Tratamiento Antirretroviral

Não se observou uma relação entre as combinações de fármacos (tipo de princípio ativo utilizado) e o grau de adesão ao tratamento $(\mathrm{F}[3,47]=1,561 ; \mathrm{p}=0,21)$. Porém, o número de comprimidos requeridos pelas diferentes combinações de fármacos foi diferente estatisticamente $(\mathrm{F}[3,50]=17,754 ; \mathrm{p}=0,000)$. Concretamente, a combinação 2ITRN+1ITRNN requeria em média $3,6(\mathrm{DP}=0,8)$ comprimidos, a combinação 2 ITRN+2IP requeria em média $8,5(\mathrm{DP}=3,1)$ comprimidos; a combinação 2 ITRN+1IP requeria em média $11,8(\mathrm{DP}=4,6)$ comprimidos, e a combinação 2 ITRN +1 IP +1 ITRNN requeria em média 5,8 $(\mathrm{DP}=3,5)$ comprimidos.

Na Tabela 2, observam-se os indicadores das qualidades dos itens, como percentagem de respostas em branco (esperada $0 \%$ ), média (se espera que não inclua o valor mínimo-máximo possível), correlação item-total corrigida pela eliminação do item em questão (esperada $>0,10$ ), e alfa de Cronbach (consistência interna) se é eliminado o item. A maioria dos itens cumpriu os critérios de qualidade esperados e não houve valores 
Tabela 3. Resultados da análise de variância de um fator: grau de adesão X carga viral (log 10).

\begin{tabular}{|c|c|c|c|c|c|c|c|}
\hline \multirow{2}{*}{$\begin{array}{l}\text { Grupo de acordo com o grau de adesão } \\
\text { (escores brutos; percentil) }\end{array}$} & \multirow{2}{*}{$\mathrm{N}$} & \multirow{2}{*}{ Média* } & \multirow{2}{*}{$\mathrm{DP}^{*}$} & \multicolumn{2}{|c|}{$\begin{array}{l}\text { Intervalo de confiança } \\
\text { para a média ao } 95 \%\end{array}$} & \multirow{2}{*}{ Mínimo } & \multirow{2}{*}{ Máximo } \\
\hline & & & & $\begin{array}{l}\text { Limite } \\
\text { inferior }\end{array}$ & $\begin{array}{l}\text { Limite } \\
\text { superior }\end{array}$ & & \\
\hline $\begin{array}{l}\text { Baixa/insuficiente (escore bruto } \leq 74 ; \\
\text { percentil } \leq 49 \text { ) }\end{array}$ & 23 & 2,14 & 2,0 & 1,2 & 3,0 & 0 & 4,8 \\
\hline $\begin{array}{l}\text { Boa/adequada (escore bruto entre } 75 \text { e } \\
79 \text {; percentil 50-85) }\end{array}$ & 24 & 1,28 & 1,7 & 0,5 & 2,0 & 0 & 5,6 \\
\hline Estrita (escore bruto $\geq 80$; percentil $\geq 85$ ) & 12 & 0,17 & 0,6 & 0,2 & 0,5 & 0 & 2,1 \\
\hline Total & 59 & 1,39 & 1,8 & 0,9 & 1,8 & 0 & 5,6 \\
\hline
\end{tabular}

Estatístico de Levene = 18,236; gl1 = 2 gl2 = 56; $\mathrm{p}=0,000$

* Carga viral transformada logaritmos (log 10) para a análise estatística.

perdidos, o que indica que todas as perguntas puderam ser respondidas. Os itens que cumpriram parcialmente os critérios de qualidade esperados são: $8,13,15,16$, 20 (Tabela 2). O indicador de confiabilidade (alfa de Cronbach) foi de 0,64 e a estrutura do questionário cumpriu as recomendações de qualidade. Os valores de pontuação total mínimos e máximos observados foram 50 e 84 , respectivamente, com pontuação total média de 74,89 (DP=5,66). Não se observou um efeito solo (floor effect, $0 \%$ ) ou teto (ceilling effect, $0 \%$ ) nas pontuações do questionário (percentagem de indivíduos que pontuam dentro dos valores mínimos e máximos possíveis do questionário; recomenda-se que seja inferior a $10 \%$ ).

Para testar a hipótese de que pacientes que mantivessem maior grau de adesão ao tratamento apresentariam menores níveis de carga viral, * realizou-se uma análise de correlação (Pearson) entre a variável grau de adesão (escore bruto obtido no questionário CEAT-VIH) e a medida de carga viral mais recente (até três meses). Os resultados indicam correlação inversa significativa entre o grau de adesão ao tratamento medido pelo CEAT-VIH e a carga viral, $(\mathrm{r}=-0,48 ; \mathrm{p}=0,000)$. Realizou-se análise de variância (Anova) de um fator, classificando a amostra em três grupos diferentes em função do grau de adesão ao tratamento medido pelo questionário CEAT-VIH (variável independente): adesão baixa/insuficiente (escore bruto $\leq 74$; percentil $\leq 49$ ), adesão boa/adequada (escore bruto entre 75 e 79; percentil 50-85) ou estrita (escore bruto $\geq 80$; percentil $\geq 85$ ). Observou-se diferenças significativas na carga viral (variável dependente) em função dos grupos $(F[2,56]=5,148 ; \mathrm{p}=0,009$; Tabela 3$)$.

Para avaliar a capacidade do questionário CEAT-VIH em detectar o nível de adesão ao tratamento ótimo necessário para a predição de uma carga viral indectável, realizou-se uma análise de curvas ROC. Mediante
Tabela 4. Ponto de corte, sensibilidade e especificidade do questionário CEAT-VIH, versão brasileira.

\begin{tabular}{ccc}
\hline $\begin{array}{c}\text { Critério (Ponto } \\
\text { de corte) }\end{array}$ & $\begin{array}{c}\% \text { Sensibilidade } \\
\text { (IC 95\%) }\end{array}$ & $\begin{array}{c}\% \text { Especificidade } \\
\text { (IC 95\%) }\end{array}$ \\
\hline$<50$ & $0,0(0,0 ; 14,4)$ & $100,0(89,9 ; 100,0)$ \\
$\leq 50$ & $4,2(0,7 ; 21,2)$ & $100,0(89,9 ; 100,0)$ \\
$\leq 62$ & $8,3(1,3 ; 27,0)$ & $100,0(89,9 ; 100,0)$ \\
$\leq 66$ & $16,7(4,8 ; 37,4)$ & $100,0(89,9 ; 100,0)$ \\
$\leq 68$ & $20,8(7,2 ; 42,2)$ & $97,1(85,0 ; 99,5)$ \\
$\leq 69$ & $20,8(7,2 ; 42,2)$ & $94,3(80,8 ; 99,1)$ \\
$\leq 70$ & $25,0(9,8 ; 46,7)$ & $91,4(76,9 ; 98,1)$ \\
$\leq 71$ & $33,3(15,7 ; 55,3)$ & $85,7(69,7 ; 95,1)$ \\
$\leq 72$ & $33,3(15,7 ; 55,3)$ & $80,0(63,1 ; 91,5)$ \\
$\leq 73$ & $41,7(22,1 ; 63,3)$ & $77,1(59,9 ; 89,5)$ \\
$\leq 74$ & $54,2(32,8 ; 74,4)$ & $71,4(53,7 ; 85,3)$ \\
$\leq 75$ & $66,7(44,7 ; 84,3)$ & $62,9(44,9 ; 78,5)$ \\
$\leq 76 * *$ & $79,2(57,8 ; 92,8)$ & $57,1(39,4 ; 73,7)$ \\
$\leq 77$ & $83,3(62,6 ; 95,2)$ & $45,7(28,8 ; 63,3)$ \\
$\leq 78$ & $91,7(73,0 ; 98,7)$ & $34,3(19,1 ; 52,2)$ \\
$\leq 79$ & $95,8(78,8 ; 99,3)$ & $31,4(16,9 ; 49,3)$ \\
$\leq 80$ & $95,8(78,8 ; 99,3)$ & $20,0(8,5 ; 36,9)$ \\
$\leq 81$ & $100,0(85,6 ; 100,0)$ & $17,1(6,6 ; 33,7)$ \\
$\leq 82$ & $100,0(85,6 ; 100,0)$ & $5,7(0,9 ; 19,2)$ \\
$\leq 83$ & $100,0(85,6 ; 100,0)$ & $2,9(0,5 ; 15,0)$ \\
$\leq 84$ & $100,0(85,6 ; 100,0)$ & $0,0(0,0 ; 10,1)$ \\
\hline
\end{tabular}

* Escore bruto CEAT-VIH

** ponto de corte ótimo

a análise das curvas ROC, foi possível identificar a sensibilidade (proporção de verdadeiros-positivos) e a especificidade (proporção de falsos-positivos) de um instrumento diagnóstico para identificar casos positivos na variável estado (grupo prognosticado, neste caso carga viral detectável, prevalência de $40,7 \%$ da amostra).

\footnotetext{
* A variável carga viral foi transformada em logaritmos para a análise estatística, pois não apresenta distribuição normal.
} 
A Figura representa a curva ROC obtida para o questionário CEAT-VIH e os indicadores de descriminação em função da carga viral.

Como se observa no gráfico, a curva ROC está distante da linha diagonal (quanto maior a curvatura da linha, maior é a capacidade de discriminação). Isso indica que a pontuação do grau de adesão ao tratamento (medido pelo CEAT-VIH) parece detectar de forma adequada os indivíduos com carga viral detectável. Essa interpretação subjetiva do gráfico confirma os resultados estatísticos, onde a área abaixo da curva é de 0,714 (IC 95\%: 0,581 a 0,824; $\mathrm{p}=0,001$ ).

A Tabela 4 apresenta os indicadores de sensibilidade e especificidade obtidos para o CEAT-VIH. O ponto de corte ótimo sugerido pela análise é de menor ou igual a 76 no questionário para adesão ao tratamento insuficiente associada a uma carga viral detectável. A esta pontuação se associa uma sensibilidade de 79,2\% e especificidade de $57,1 \%$.

Para identificar a relação entre as percepções e expectativas com o tratamento e o grau de adesão ao tratamento, realizou-se uma análise de correlação (Pearson) entre as variáveis. Foram observadas associações estatisticamente significativas para as expectativas e otimismo em relação ao tratamento $(r=0,51 ; p=0,000)$ e percepção de dificuldades $(\mathrm{r}=-0,27 ; \mathrm{p}=0,034)$, com maior grau de adesão ao tratamento. Ou seja, os indivíduos com expectativas positivas e otimistas com relação ao tratamento e aqueles que não perceberam dificuldades apresentaram um maior grau de cumprimento do tratamento. Por outro lado, a percepção de mudanças (positivas ou negativas) não foi associada de forma significativa com a adesão ao tratamento $(r=0,22 ; \mathrm{p}=0,090)$.

\section{DISCUSSÃO}

O grau de adesão informado parece não sofrer influência das características sociodemográficas da amostra. Os participantes do presente estudo apresentavam perfil socioeconômico baixo e médio baixo, com nível de estudo fundamental e dispersão no que diz respeito à idade (entre 24 e 72 anos). Outros estudos ${ }^{6,18}$ também não consideraram o nível socioeconômico como bom preditivo do grau de adesão ao tratamento, exceto em situações de extrema pobreza, o que não foi o caso da amostra atual. Do mesmo modo, a associação entre grau de adesão e idade não está clara na literatura. ${ }^{6,7,18}$ A maioria dos estudos ${ }^{1-3,5,9,11,15,16}$ discute que há fatores mais importantes do que características sociodemográficas concretas, como a idade, escolaridade ou o nível socioeconômico. Entre os fatores que dificultam a adesão a um tratamento tão complexo e por tempo

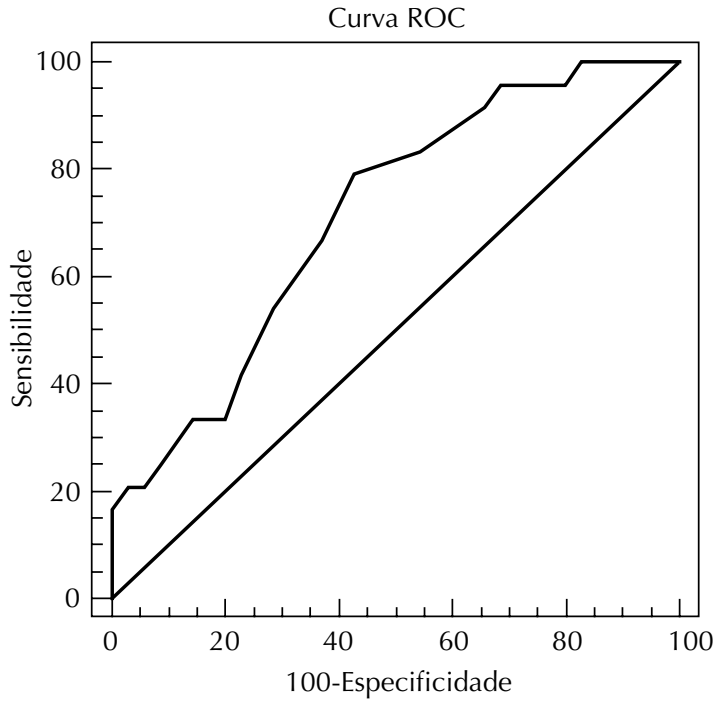

Sensibilidade: 79,2

Especificidade: 57,1

Critério (Ponto de corte): $\leq 76$

Figura. Curvas ROC obtidas para o questionário CEAT-VIH e indicadores de sensibilidade e especificidade.

indefinido, citam-se isolamento social, estresse, preconceito, falta de informação e conseqüente falta de apoio afetivo e social e de um serviço de saúde acessível. Outros estudos ${ }^{6,14,17}$ chegaram a relacionar estas situações com a maior vulnerabilidade destes pacientes ao desenvolvimento de resistências à medicação antiretroviral e ao adoecimento (possivelmente mediada pela falta de cumprimento do tratamento).

$\mathrm{Na}$ mesma linha, Catz et $\mathrm{al}^{3}$ apontaram que a complexidade do regime terapêutico também pode exercer influência sobre a adesão ao tratamento. No presente estudo foi observada relação inversa entre o número de comprimidos receitados e o grau de adesão identificado pelo questionário, porém não estatisticamente significativo, confirmando os achados de Nemes et al.* No entanto, os pacientes que ingeriam maior quantidade de comprimidos apresentavam carga viral mais alta (relação estatisticamente significativa), podendo indicar possíveis dificuldades no seguimento desta pauta. A diminuição do grau de adesão e o aumento da carga viral se observavam mais explicitamente para os indivíduos com ingestão igual ou superior a dez comprimidos. Resultados similares foram descritos também em outros estudos. ${ }^{3}$ Antecipar que este tipo de tratamento pode constituir em risco para uma adesão estrita (e portanto risco de desenvolvimento de resistências ao fármaco) pode ajudar o especialista a estabelecer um regime de tratamento mais personalizado às capacidades de cada paciente para seguir o tratamento.

* Nemes MIB, Marinho, MFS, Kalichman A, Grangeiro A, Alencar RS, Lopez JF. Prevalência da aderência e fatores associados. In: Nemes MIB, (Org.) Avaliação da aderência ao tratamento por antiretrovirais em usuários de ambulatórios do sistema público de assistência à Aids no Estado de São Paulo. Brasília (DF): Coordenação Nacional DST/Aids; 2000. p. 44-76. Série Avaliação $n^{\circ} 1$. 
Embora os pacientes do presente estudo tenham apresentado certa variabilidade nos níveis de carga viral no sangue, observou-se alta percentagem de indivíduos com caga viral indetectável (59,3\%). Isso sugere que a maioria dos pacientes estava recebendo um tratamento antiretroviral ótimo e com uma percentagem relativamente alta de adesão e seguimento das indicações médicas.

Ademais, observou-se correlação significativa entre a quantidade de vírus no sangue e a adesão ao tratamento medida pelo questionário CEAT-VIH. Portanto, partindo-se do princípio de que a carga viral é um marcador biológico indicador de sucesso com o tratamento antiretroviral, pode-se dizer que o auto-relato do grau de adesão é um método fiável de avaliação do comportamento de ingestão do tratamento farmacológico.

A análise das características psicométricas do questionário na amostra brasileira permitiu confirmar suas qualidades. Os indicadores referentes à qualidade dos itens que compõem o questionário (p. ex.: valores perdidos, correlação item-total corrigida, efeito teto e solo) foram adequados.

Em relação à sua utilização em pesquisa, o instrumento mostrou-se confiável e válido (por meio da validade relacionada a um critério externo - carga viral; e da validade diagnóstica (preditiva): sensibilidade e especificidade para a detecção entre pacientes com um diferente nível de carga viral). A análise estatística utilizada no presente estudo permitiu estabelecer um ponto de corte para o questionário. Porém, determinar o ponto de corte ótimo para um instrumento de avaliação auto-aplicável é um problema complexo. As curvas ROC analisadas facilitam a decisão, por meio dos indicadores de sensibilidade e especificidade possíveis para o instrumento. No entanto, estes indicadores não resolvem totalmente o problema, pois o objetivo para o qual se busca um ponto de corte (p. ex.: atenção clínica ou pesquisa) pode determinar também a necessidade de uma precisão mais ou menos restrita. Para o presente trabalho, o objetivo principal foi proporcionar evidências da validade do questionário para a identificação de indivíduos em risco para um seguimento inadequado do tratamento ou fracasso terapêutico por falta de adesão ao tratamento. Por tratar-se de estudo preliminar, estes dados devem ser tomados com cautela.

Por último, trabalhos anteriores* indicaram que expectativas ou crenças favoráveis com relação ao tratamento farmacológico podem facilitar seu maior seguimento. Esses resultados também se confirmaram com o presente estudo, onde as expectativas e otimismo com o tratamento, a percepção de ausência de dificuldades e problemas com o tratamento foram associados ao maior grau de adesão ao tratamento. Promover um sentido de esperança ou gerar expectativas positivas com o tratamento nos pacientes HIV-positivos pode ser importante, pois ao surgir dificuldades, as expectativas favoráveis e otimistas incrementam os esforços das pessoas para alcançar os objetivos, por exemplo, tomar regularmente o tratamento.

Concluindo, o Questionário para Avaliação da Adesão ao Tratamento Anti-retroviral é uma ferramenta potente, eficiente, útil, que oferece vantagens importantes devido à sua aplicação prática em contexto de pesquisa e/ou aplicada no âmbito da infecção pelo HIV e Aids.

\section{AGRADECIMENTOS}

À psicóloga Aline Eder pela coleta de dados, e ao apoio do Centro Municipal de Atendimento às DST/Aids Secretaria Municipal da Saúde de Porto Alegre (RS).

\footnotetext{
* Remor E. Does positive expectancies and optimism related to the antiretroviral treatment enhance adherence to treatment in people living with HIV? Book of Abstracts of the 17 $7^{\text {th }}$ Conference of the European Health Psychology Society; 2003 Sep 24-27; EHPS: Kos Island, Greece. Pág. 97.
} 


\section{REFERÊNCIAS}

1. Álvarez-Váldes MVG, Cruz-Troca J. Adherencia y fallo terapéutico en el seguimiento de una muestra de sujetos VIH+: algunas hipótesis desde la psicología. Psicothema. 2003;15(2):227-33.

2. Ballester R, Reinoso I, Garcia S, Campos A. Adherencia al tratamiento en la infección por $\mathrm{VIH}$. Análisis Mod Conducta. 2000;26(109):689-718.

3. Catz SL, Kelly JA, Bogart LM, Benotsch EG, McAuliffeTL. Patterns, Correlates, and Barriers to Medication Adherence Among Persons Prescribed New Treatments for HIV Disease. Health Psychol. 2000;19(2):124-33.

4. Castro EK, Remor EA. Aspectos psicossociais e HIV/Aids: um estudo bibliométrico (1992-2002) comparativo dos artigos publicados entre Brasil e Espanha. Psicol Refl Crit. 2004;1(2)7:243-50.

5. Gordillo V, del Amo J, Soriano V, Gonzalez-Lahos J. Sociodemographic and psychological variables influencing adherence to a antiretroviral therapy. AIDS 1999;13(13):1763-9.

6. Jordan, MS, Lopes JF, Okazaki E, Komatsu, CL, Nemes, MIB. Aderência ao tratamento anti-retroviral em AIDS: revisão da literatura médica. In: Teixeira, PR, Paiva $\mathrm{V}$, Shimma E, organizadores. Tá difícil de engolir? Experiências de adesão ao tratamento anti-retroviral em São Paulo. São Paulo: NEPAIDS; 2000. p. 5-22.

7. Leite SN, Vasconcellos, MPC. Adesão à terapêutica medicamentosa: elementos para a discussão de conceitos e pressupostos adotados na literatura. Ciênc Saúde Coletiva. 2003;8(3):775-82.

8. Lignani Jr. L, Greco, DB, Carneiro M. Avaliação da aderência aos anti-retrovirais em pacientes com infecção pelo HIV/Aids. Rev Saúde Pública. 2001;35(6):495-501.

9. Murphy DA, Marelich WD, Hoffman D, Steers WN. Predictors of antiretroviral adherence. AIDS Care. 2004;16(4):471-84
10. Metz CE. Basic principles of ROC analysis. Semin Nucl Med. 1978;8(4):283-98.

11. Remor E. Valoración de la adhesión al tratamiento antirretroviral en pacientes $\mathrm{VIH}+$. Psicothema. $2002 ; 14(2): 262-7$.

12. Remor E. Aspectos psicossociais na era dos novos tratamentos da AIDS. Psic Teor Pesq. 2002;18(3): 283-7.

13. Remor E. Cuestionario para la evaluación de la adhesión al tratamiento antirretroviral (CEAT-VIH): estudio internacional. Rev Humanitas. 2006;3:80-81.

14. Remor E, Penedo FJ, Shen B-J, Schneiderman N. Perceived stress is associated with CD4+ cell decline in men and women living with HIV/AIDS in Spain. AIDS Care. 2007;19(2):215-9.

15. Ruiz Perez I, Labry-Lima AO, Delgado-Dominguez CJ, Herrero MM, Roca NM, Liaño JP et al. Impacto del apoyo social y la morbilidad psíquica en la calidad de vida en pacientes tratados con antirretrovirales. Psicothema. 2005;17(2):245-9.

16. Tuldra A, Fumaz CR, Ferrer MJ, Bayés R, Arnó A, Balagué $M$, et al. Prospective randomized two-arm controlled study to determine the efficacy of a specific intervention to improve long-term adherence to highly active antiretroviral therapy. I Acquir Immune Defic Syndr. 2000;25(3):221-8.

17. Weiss L, French T, Finkelstein R, Waters M, Mukherjee $\mathrm{R}$, Agios B. HIV-related knowledge and adherence to HAART. AIDS Care. 2003;15(5):673-79.

18. World Health Organization. Adherence to long-term therapies: Evidence for action. Geneva: WHO; 2003.

19. Zweig MH, Campbell G. Receiver-operating characteristic (ROC) plots: a fundamental evaluation tool in clinical medicine. Clin Chem. 1993; 39(4): 561-77.

J Milner-Moskovics foi apoiada pela Coordenação de Aperfeiçoamento de Pessoal de Nível Superior (CAPES-PUCRS nº 2837/05-6 - bolsa de doutorado). 


\section{ANEXO}

Questionário para a Avaliação da Adesão ao Tratamento Antiretroviral (CEAT-VIH, Versão em português [Brasil])

Durante a última semana

1. Deixou de tomar sua medicação alguma vez?

2. Se alguma vez sentiu-se melhor, deixou de tomar sua medicação?

3. Se alguma vez depois de tomar sua medicação sentiu-se pior, deixou de tomá-la?

4. Se alguma vez se sentiu triste ou deprimido, deixou de tomar sua medicação?

\begin{tabular}{|l|l|l|l|l|}
\hline Sempre & $\begin{array}{c}\text { Mais da metade } \\
\text { das vezes }\end{array}$ & $\begin{array}{c}\text { Aproximadamente } \\
\text { a metade das vezes }\end{array}$ & $\begin{array}{c}\text { Alguma } \\
\text { vez }\end{array}$ & $\begin{array}{c}\text { Nenhuma } \\
\text { vez }\end{array}$ \\
\hline & & & & \\
\hline & & & & \\
\hline & & & & \\
\hline & & & & \\
\hline
\end{tabular}

5. Lembra-se que remédios está tomando nesse momento? (escrever os nomes)

6. Como é a relação que mantém com o seu médico?

\begin{tabular}{|c|c|c|c|c|}
\hline Ruim & Um pouco ruim & Regular & Pode melhorar & Boa \\
\hline
\end{tabular}

7. Quanto você se esforça para seguir com o tratamento?

8. Quanta informação você tem sobre os medicamentos que toma para o HIV?

9. Quanto benefício pode lhe trazer o uso destes medicamentos?

10. Considera que sua saúde melhorou desde que começou a tomar os medicamentos para o HIV?

11. Até que ponto sente-se capaz de seguir com o tratamento?

\begin{tabular}{|l|l|l|l|l|}
\hline Nada & Pouco & Regular & Bastante & Muito \\
\hline & & & & \\
\hline & & & & \\
\hline & & & & \\
\hline & & & & \\
\hline & & & & \\
\hline
\end{tabular}

12. Normalmente está acostumado a tomar a medicação na hora certa?

13. Quando os resultados dos exames são bons, seu médico costuma utilizá-los para Ihe dar ânimo e motivação para seguir com o tratamento?

\begin{tabular}{|c|c|c|c|c|}
\hline $\begin{array}{c}\text { Não, } \\
\text { nunca }\end{array}$ & $\begin{array}{c}\text { Sim, } \\
\text { alguma } \\
\text { vez }\end{array}$ & $\begin{array}{c}\text { Sim, aproximada- } \\
\text { mente a metade } \\
\text { das vezes }\end{array}$ & $\begin{array}{c}\text { Sim, } \\
\text { muitas } \\
\text { vezes }\end{array}$ & $\begin{array}{c}\text { Sim, } \\
\text { sempre }\end{array}$ \\
\hline & & & & \\
\hline & & & & \\
\hline
\end{tabular}

14. Como sente-se em geral com o tratamento desde que começou a tomar seus remédios?

\begin{tabular}{|l|l|l|l|l|}
\hline Muito insatisfeito & Insatisfeito & Indiferente & Satisfeito & Muito satisfeito \\
\hline
\end{tabular}

15. Como avalia a intensidade dos efeitos colaterais relacionados com o uso dos medicamentos para o HIV?

\begin{tabular}{|c|c|c|c|c|}
\hline Muito intensos & Intensos & Medianamente intensos & Pouco intensos & Nada intensos \\
\hline
\end{tabular}

16. Quanto tempo acredita que perde ocupando-se em tomar seus remédios?

\begin{tabular}{|c|c|c|c|c|}
\hline Muito tempo & Bastante tempo & Regular & Pouco tempo & Nada de tempo \\
\hline
\end{tabular}

17. Que avaliação tem de si mesmo com relação a toma dos remédios para o HIV?

\begin{tabular}{|c|c|c|c|c|}
\hline Nada cumpridor & Pouco cumpridor & Regular & Bastante & Muito cumpridor \\
\hline
\end{tabular}

18. Quanta dificuldade tem para tomar a medicação?

\begin{tabular}{|c|c|c|c|c|c|c|}
\hline Muita dificuldade & Bastante dificuldade & Regular & Pouca dificuldade & \multicolumn{3}{|c|}{ Nenhuma dificuldade } \\
\hline & & & & & SIM & $\mathrm{NÃO}$ \\
\hline \multicolumn{5}{|c|}{$\begin{array}{l}\text { 19. Desde que está em tratamento alguma vez deixou de tomar sua medicação um dia completo, ou mais } \\
\text { de um? [Se responde afirmativamente, Quantos dias aproximadamente?] }\end{array}$} & & \\
\hline \multicolumn{5}{|c|}{$\begin{array}{l}\text { 20. Utiliza alguma estratégia para lembrar-se de tomar a medicação? } \\
\text { Qual? }\end{array}$} & & \\
\hline
\end{tabular}

